\title{
Treatment for periodic paralysis (Review)
}

\author{
Sansone V, Meola G, Links T, Panzeri M, Rose MR
}

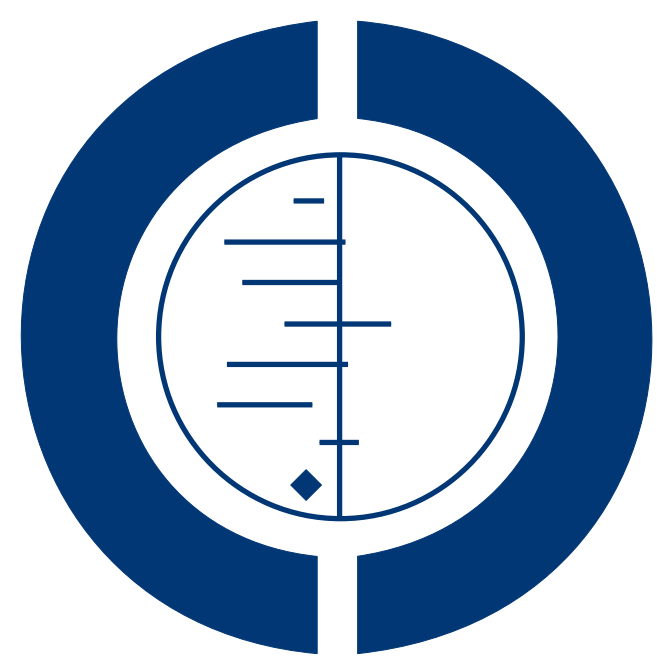

\section{THE COCHRANE COLLABORATION $^{\circledR}$}

This is a reprint of a Cochrane review, prepared and maintained by The Cochrane Collaboration and published in The Cochrane Library 2008, Issue 3

http://www.thecochranelibrary.com

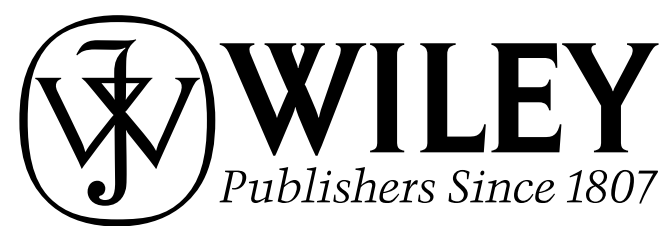


TABLE OF CONTENTS

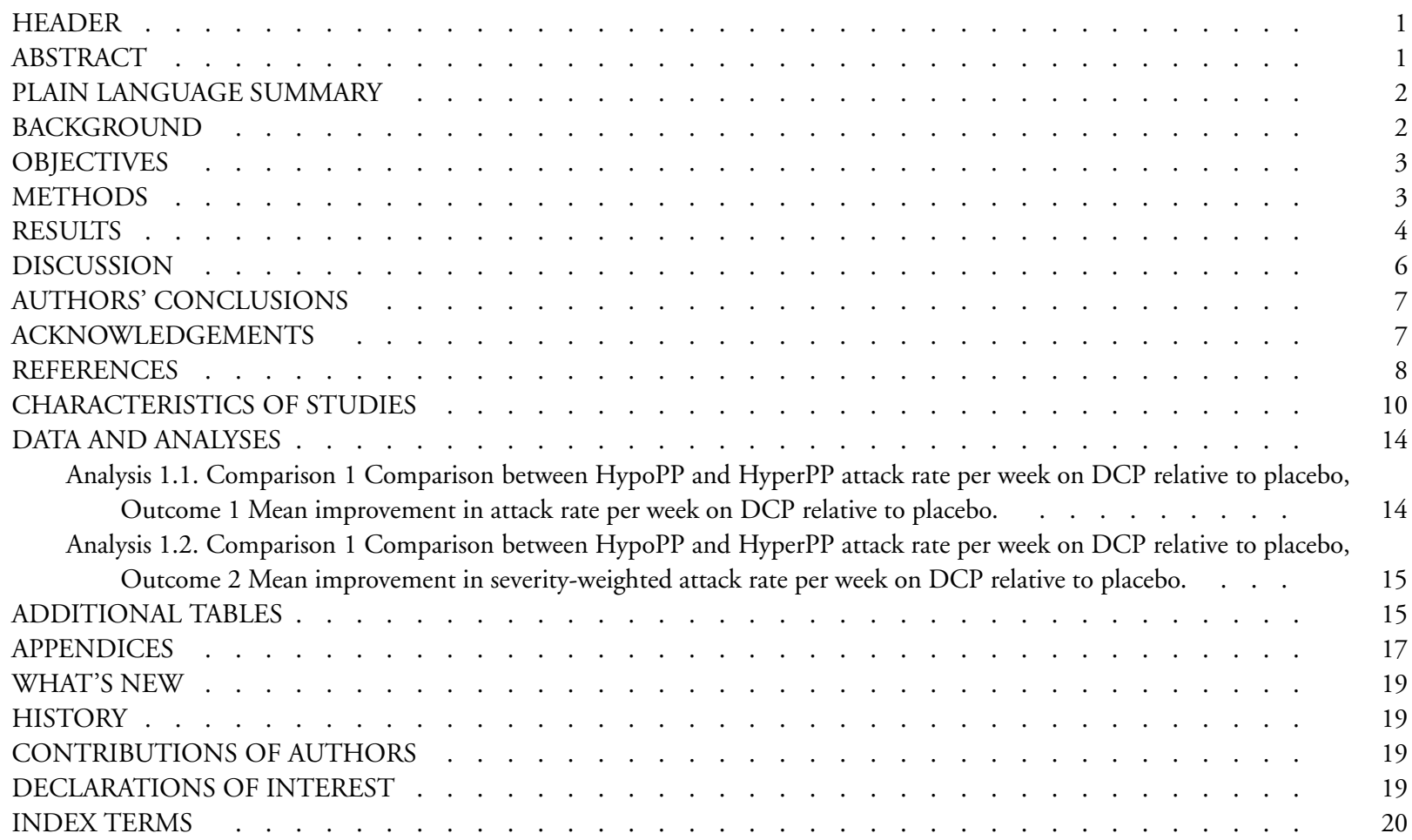




\title{
[Intervention Review]
}

\section{Treatment for periodic paralysis}

\author{
Valeria Sansone ${ }^{1}$, Giovanni Meola ${ }^{1}$, Thera Links $^{2}$, Marta Panzeri $^{3}$, Michael R Rose ${ }^{4}$ \\ ${ }^{1}$ Department of Neurology, University of Milan, Milan, Italy. ${ }^{2}$ Department of Endocrinology, University of Groningen, Groningen, \\ Netherlands. ${ }^{3}$ Department of Neurology, Policlinico San Donato Milanese, Milan, Italy. ${ }^{4}$ Department of Neurology, King's College \\ Hospital, London, UK \\ Contact address: Valeria Sansone, Department of Neurology, University of Milan, Istituto Policlinico San Donato, San Donato Milanese, \\ Milan, 20097, Italy. valeria.sansone@unimi.it.
}

Editorial group: Cochrane Neuromuscular Disease Group.

Publication status and date: Edited (no change to conclusions), published in Issue 3, 2008.

Review content assessed as up-to-date: 13 November 2007.

Citation: Sansone V, Meola G, Links T, Panzeri M, Rose MR. Treatment for periodic paralysis. Cochrane Database of Systematic Reviews 2008, Issue 1. Art. No.: CD005045. DOI: 10.1002/14651858.CD005045.pub2.

Copyright (c) 2008 The Cochrane Collaboration. Published by John Wiley \& Sons, Ltd.

\section{A B S T R A C T}

\section{Background}

Primary periodic paralyses are rare inherited muscle diseases characterised by episodes of flaccid weakness affecting one or more limbs, lasting several hours to several days, caused by mutations in skeletal muscle channel genes.

\section{Objectives}

The objective of this review was to systematically review treatment of periodic paralyses.

\section{Search methods}

We searched the Cochrane Neuromuscular Disease Group Trials Register, MEDLINE (from January 1966 to July 2007), and EMBASE (from January 1980 to July 2007) and any other available international medical library sources from the University of Milan for randomised trials.

\section{Selection criteria}

We included randomised (including cross-over studies) and quasi-randomised trials in participants with primary periodic paralyses, in which any form of treatment, including physical therapy and alternative therapies, was compared to placebo or another treatment.

\section{Data collection and analysis}

Our primary outcome measure was the change in attack severity or frequency by eight weeks from the start of treatment.

Our secondary outcome measures were: change in muscle strength and mass; change in Quality of Life, using Short Form 36 (SF36) or similar; preference of treatment strategy; adverse effects at eight weeks.

\section{Main results}

Three studies met our inclusion criteria. In one study dichlorphenamide (DCP) vs placebo was tested in two groups of participants: 42 with hypokalemic periodic paralysis (HypoPP) and 31 with hyperkalemic periodic paralysis (HyperPP), based on clinical criteria. Thirty-four of 42 participants with hypokalemic periodic paralysis completed both treatment phases. For the 34 participants having attack rate data for both treatment phases, the mean improvement in attack rate $(P=0.02)$ and severity-weighted attack rate $(P=$ 0.01) on DCP relative to placebo were statistically significant. Fifteen preferred DCP, three placebo and six their baseline medication. 
Twenty-four of 31 participants with hyperkalemic periodic paralysis completed both treatment phases: for the 16 participants who had attack rate data for both treatment phases, the mean improvement in attack rate $(P=0.006)$ and in severity-weighted attack rate $(P=$ 0.02) on DCP relative to placebo were significant. Fifteen preferred DCP, one placebo and five their baseline medication.

Acetazolamide proved to improve muscle strength in eight participants with HypoPP in one other study and pinacidil, a potassium channel opener, also improved muscle strength in 2/4 participants with HypoPP in a third study.

\section{Authors' conclusions}

The largest included study that met our inclusion criteria suggested that DCP was effective in the prevention of episodic weakness in both hypokalemic and hyperkalemic periodic paralyses. The other two studies provide some evidence that either acetazolamide or pinacidil may improve muscle strength. However we still lack sufficient evidence to provide full guidelines for the treatment of people with periodic paralysis.

\section{PLAIN LANGUAGE SUMMARY}

\section{Treatment for periodic paralysis}

Muscle weakness and attacks of paralysis are two important features of periodic paralyses. Paralytic attacks occur in acute episodes and can be incapacitating. Attacks may last from several hours to several days according to the type of muscle channel involved. In some cases permanent muscle weakness can also occur. We are unsure whether such permanent muscle weakness is more likely to develop if the frequency of attacks is high and therefore might be less likely to occur if attacks are fully prevented by treatment. Although the treatment of choice in periodic paralysis is generally considered to be acetazolamide, there is no standardised treatment regimen and no consensus as to when to start treatment. We do not know if acetazolamide treatment prevents any permanent weakness that may occur.

We found two small studies demonstrating an improvement of muscle strength with pinacidil and acetazolamide. There was only one trial considering treatment of paralytic attacks, demonstrating a decrease in the severity and frequency of the attacks using diclorophenamide.

We did not find other randomised or quasi-randomised studies, but only case reports and anecdotal articles using other drugs to reduce paralyses attacks. Further research is needed to determine the best treatment for reducing the frequency and severity of attacks and to treat or prevent permanent muscle weakness.

\section{B A C K G R O U N D}

The primary periodic paralyses (PP) are rare muscle diseases (estimated population prevalence of one per 100,000) affecting males and females of all ages, characterised by episodes of flaccid paresis affecting one or more limbs. They result from genetic disorders of ion channels called "channelopathies".

Hypokalemic periodic paralysis (HypoPP) is caused in $80 \%$ of cases by point mutations in the voltage-gated calcium channel gene on chromosome 1 (Fontaine 1994; Jurkat-Rott 1994; Ptacek 1994b; Rojas 1991). So far, three calcium channel mutations have been described (Arg528His, Arg1239His, Arg1239Gly). HypoPP gene may also be due to a gain-of function on the voltagegated sodium channel on chromosome 17 (Arg 672His/Gly/Ser, Arg669His) (Jurkat-Rott 2000; Sternberg 2001).
Hyperkalemic periodic paralysis (HyperPP) is caused by point mutations in the voltage-gated sodium channel on chromosome 17 (Fontaine 1990; Ptacek 1991). Sodium channelopathies include not just hyperkalemic periodic paralysis but also paramyotonia congenita, potassium-aggravated myotonia, (McClatchey 1992; Ptacek 1991; Ptacek 1992; Heine 1993). So far, about 30 point mutations in the sodium channel gene have been described.

Andersen-Tawil syndrome (ATS) is another primary periodic paralysis characterised by episodes of flaccid weakness in the context of normal, low or high serum potassium levels, sometimes with severe cardiac arrhythmias, including long QT syndrome, and skeletal and facial dysmorphic features (Andersen 1971; Sansone 1997; Tawil 1994). Mutations in the potassium channel gene $\mathrm{KCNJ} 2$, are the primary cause of ATS. Twenty-one mutations have been found in 30 families and have been found to cause the 
developmental, cardiac and muscle episodic electrical phenotypes of the syndrome (Plaster 2001). Functional and clinical characterisation of mutations on chromosome 17 on the KCNJ2 gene results in a loss or suppression of the function of the channel Kir2.1, which is an inward rectifier, have been associated with LQT7 (TristaniFirouzi 2002). These mutations result in a reduction of the function of the channel (Bendahhou 2003, Donaldson 2004).

Diagnostic criteria for primary periodic paralyses have been proposed by an expert committee at the 87th European Neuromuscular Centre (ENMC) International Workshop in 2000 (Table 1; Table 2). These included mainly clinical criteria (evidence of flaccid paresis affecting one or more limbs with absent deep tendon reflexes during an attack with the typical classical profile of triggers, age at onset, duration of the attack, positive family history, response to potassium intake) and laboratory confirmation of potassium fluctuation (decrease or increase) during the attack. Additional criteria were exclusion of other secondary causes of hypoor hyperkalemia and the decremental response of the compound muscle potential after repetitive stimulation (McManis 1986). Serum potassium is normal between attacks.

In addition to the attacks of weakness, periodic paralysis may be characterised by permanent muscle weakness and a limb-girdle myopathy may develop over time (Dalakas 1983; Links 1990). It is unclear whether this is directly related to the frequency and severity of the episodes of flaccid weakness which result in cumulative damage to the muscle fibers (Dalakas 1983; Links 1990).

Evidence that potassium intake reduces the severity and frequency of the attacks of weakness in the hypokalemic periodic paralysis, has long been known. However, even regular potassium intake may fail to prevent attacks and escalating use of potassium may cause gastrointestinal problems. Nonetheless, the serum potassium abnormalities in the PP and the response to potassium administration, provided a rationale for the utilisation of drugs capable of affecting serum potassium levels, such as the carbonic anhydrase inhibitors (Griggs 1970; Links 1988).

Acetazolamide is the most commonly used of the carbonic anhydrase inhibitors, based on the results of non-randomised, singleblind trials in hypokalemic periodic paralysis (Griggs 1970; Ptacek 1994a; Resnick 1968). Dichlorphenamide (DCP) is an alternative carbonic anhydrase inhibitor (Dalakas 1983) with similar but milder side effects compared with acetazolamide. In general, studies have aimed to show a reduction in the frequency and severity of the attacks using these drugs (Bendahhou 2001; Griggs 1970; Links 1988; Links 1994). Gastrointestinal disturbances (anorexia, nausea and vomiting), drowsiness, paraesthesias, and electrolyte imbalance are the most common long term side effects of carbonic anhydrase inhibitors. Use of steroids and furosemide, during treatment with carbonic anhydrase inhibitors, may precipitate side effects.

Alternative treatments in hyperkalemic periodic paralysis have included reduction of potassium levels either by reducing intake (Dalakas 1983; Links 1988) or the use of diuretics such as hydrochlorothiazide (Links 1994; Ricker 1983).

The molecular genetic and cellular electrophysiological progress in the skeletal muscle channelopathies has been significant. Despite this biomolecular progress, effective treatment options are limited. The evidence for current treatments for the periodic paralyses is limited and thus there is no agreed consensus on treatment for PP. There continues to be debate as to the best therapy both in terms of efficacy and side effect profile. More important, given the possibility that unrecognised or untreated attacks of periodic paralysis may contribute to the appearance of permanent muscle weakness in later life, there are no data on preventive treatment, the best time to start such treatment, or the treatment of the limbgirdle myopathy if it has already occurred.

\section{O B JE C T I VES}

The objective of this review is to systematically review treatment of periodic paralyses.

\section{METHODS}

\section{Criteria for considering studies for this review}

\section{Types of studies}

We included all the randomised controlled studies (including crossover studies) and quasi randomised trials in which any form of treatment for primary periodic paralysis was compared with placebo or another therapy. Open trials and single case studies have been included in the discussion, but not in the review.

\section{Types of participants}

We included all participants with a primary periodic paralyses diagnosed according to defined criteria of the ENMC International Workshop for Periodic Paralysis (unpublished data). 


\section{Types of interventions}

We included any treatment for periodic paralysis including drugs, alternative therapies and physical therapies.

\section{Types of outcome measures}

\section{Primary outcomes}

Our primary outcome measure was the reduction in attack severity or frequency after at least eight weeks of treatment.

\section{Secondary outcomes}

The following secondary outcome measures were considered as defined by our initial protocol:

1. Change in muscle strength determined with manual muscle strength testing according to the 5-point Medical Research Council (MRC) scale or by dynamometric strength testing after at least eight weeks of treatment.

2. Change in muscle mass, determined by dual energy $x$-ray absorptiometry (DEXA) after at least eight weeks of treatment.

3. Change in Quality of Life, measured with Short Form 36 (SF36) or similar after at least eight weeks of treatment.

4. Preference of treatment strategy ascertained after at least eight weeks of treatment.

5. Adverse effects occurring by eight weeks of treatment excluding those events considered likely to have been induced by the withdrawal of drugs used prior to entering the study.

\section{Search methods for identification of studies}

\section{Electronic searches}

We searched the Cochrane Neuromuscular Disease Group Trials Register, MEDLINE (from January 1966 to July 2007), and EMBASE (from January 1980 to July 2007) for randomised trials and any other available international medical library sources from the University of Milan using the terms 'periodic paralysis', 'hypokalemic periodic paralysis', 'hyperkalemic periodic paralysis', 'normokalemic periodic paralysis', Andersen's syndrome, Andersen-Tawil syndrome, periodic paralysis and cardiac arrhythmias' as the search terms. We reviewed the bibliographies of the randomised controlled trials identified.

See Appendix 1 and Appendix 2 for MEDLINE and EMBASE strategies.

\section{Data collection and analysis}

\section{Selection of studies}

Three authors (VS, MP and TL) independently screened the abstracts of potential trials retrieved from the searches. After reading the abstracts, the papers of those studies that appeared to meet the review inclusion criteria were obtained. These papers were then read in detail and an inclusion/exclusion criteria form was completed. All the authors were in agreement with the selection of studies for inclusion in this review.

\section{Data extraction and management}

Three authors independently extracted the data of the studies onto a data extraction form.

\section{Assessment of risk of bias in included studies}

We assessed the quality of each study in terms of explicit inclusion and exclusion criteria, explicit outcome measures, secure method of randomisation, concealment of allocation, observer and participant blinding, completeness of follow-up and intention to treat analysis. Each aspect was graded with the following scale:

A: adequate

B: unclear

C: inadequate

D: not done

\section{Data synthesis}

If the data extracted had been sufficiently similar and of sufficient quality, statistical analyses would have been performed using the Review Manager 4.2 software. We would have expressed the results as mean difference and $95 \%$ confidence intervals for continuous data had the mean values of the outcomes, the standard deviations of the outcomes and the number of participants on whom the outcome was assessed in both the treated group and placebo been available in detail. However, although four studies were selected that met our inclusion/exclusion criteria these did not have overlapping patient groups or outcome measures thus limiting data analysis.

\section{RES U L T S}

\section{Description of studies}

See: Characteristics of included studies; Characteristics of excluded studies. 
The searches found a total of 539 papers. However there were many duplicated papers from different databases. Many were papers considering treatment in secondary periodic paralysis and were therefore excluded. Other papers were reviews and did not report on clinical trials. Seventeen papers remained. Of the 17 articles remaining, 11 were case reports, six were clinical trials. Of the articles reporting clinical trials, we excluded all the studies that were not randomised, and that did not fit the criteria for considering the study in this review leaving just three papers reporting four studies. Of these four studies, two (Ligtenberg 1996; Links 1988) did not include our primary outcome measure having no data on the reduction, if any, in the frequency and severity of attacks. They reported change in muscle strength, which was one of the secondary outcomes for our review, and demonstrated an improvement in muscle strength with acetazolamide (Links 1988) and pinacidil (Ligtenberg 1996).

The third publication (Tawil 2000), described two multicentre randomised, double blind, placebo-controlled cross-over trials: one involving 42 participants with HypoPP, and the other involving 31 participants with HyperPP. In each trial, two eight-week treatment periods were separated by a washout period of at least nine weeks; participants were their own controls. Patients were randomised to Dichlorophenamide (DCP) or placebo in the first eight-week period, then they were crossed to the other medication after the wash out period, for another eight-week period.

The primary outcome variable in the HypoPP trial was the occurrence of an intolerable increase in attack frequency or severity, necessitating withdrawal from the treatment phase. This end point could occur at any time during a nine-week phase, and was distinguished from participant withdrawal or dropout because of adverse effects or other reasons. Secondary outcomes included 1) the average number of attacks per week over the final eight weeks of each phase, 2) the severity-wieghted attack rate (calculated by averaging the severity grades for each attack per week over the 8week period) and, 3) the participants' preferred treatment.

The primary outcome variable in the HyperPP trial was the attack rate (average number of attacks per week over the final eight weeks of each phase). Secondary outcomes were; 1) severity-weighted attack rate and, 2) the participants' preferred treatment.

\section{Risk of bias in included studies}

The methodological quality of the included studies was adequate in all the aspects considered, except for drop out rates (see Table 3). Periodic paralyses are rare diseases so that a placebo-controlled crossover design as that created in the studies by Tawil and coworkers was necessary to create a parallel group in the study design. The Tawil trials were randomised with a computer-generated randomisation plan by using VAX-11 Fortran, one for each diagnostic group, which included stratification by site and blocking to ensure that each site had approximately the same number of participants assigned to each treatment sequences. At the baseline, there were no significant differences between the groups, in terms of number of participants, age, mean attack rate per week and number receiving prophylactic treatment. The number of participants who completed both treatment phases were 34/42 (81\%) for the HypoPP trial and 24/31 (77.4\%) for the HyperPP trial. The trials by Links 1988; and Ligtenberg 1996 were described as randomised but the method of randomisation was not given. No drop-outs were recorded in either of these two studies.

\section{Effects of interventions}

The results of our search found four eligible studies.

The paper by Tawil 2000 reported two trials: a trial of 42 subjects HypoPP and a trial of 31 subjects with HyperPP both using dichlorphenamide (DCP). A third trial used acetazolamide in eight subjects with HyopPP (Links 1988), while a fourth used perindopril in four subjects with HypoPP (Ligtenberg 1996).

\section{HypoPP}

In the HypoPP trial by Tawil $200042 \mathrm{HypoPP}$ patients were enrolled with 22 assigned to the placebo/DCP sequence, and 20 to the DCP/placebo sequence. Thirty-four of 42 participants completed both treatment phases. Eight participants withdrew from the trial: three dropped out in the first phase of run-in; two dropped out in the first nine-week wash out period; three dropped out in the last eight-week treatment phase. Of these last three participants two were on DCP and they dropped out due to adverse effects, and the other one was taking placebo and was lost to follow-up.

Of the 34 participants who remained, 15 reached the end point of an intolerable increase in attack frequency or severity. Of the 13 patients who exhibited a preference, 11 reached the end point while taking placebo and two while taking DCP.

For the 34 participants having attack rate data while on DCP, the mean improvement in attack rate on DCP relative to placebo was statistically significant $(\mathrm{P}=0.02)$. The mean improvement in severity-weighted attack rate was statistically significant $(P=0.01)$ on DCP relative to placebo. Fifteen of the 34 participants reached the end point in at least one of the treatment phases. When these were included in the analyses, the statistical significance of the treatment became more evident $(\mathrm{P}=0.001$ for attack rate, $\mathrm{P}=$ 0.007 for severity-weighted attack rate).

When asked in a blinded fashion at the end of trial what treatment they preferred, 15 preferred DCP, three placebo and six their baseline medication, acetazolamide (see Table 4).

Most of the reported adverse events were those commonly associated with carbonic anhydrase inhibitors. The most common 
symptoms were confusion, difficulty with memory, difficulty concentrating, irritability, and depression. These adverse events accounted for the two dropouts related to medication side effects (dizziness, difficulty in concentration).

The trials by Links 1988 and Ligtenberg 1996 were short term studies focussing on the effects of acetazolamide and pinacidil on muscle strength and they did not assess the effects of these drugs on attack frequency or severity. In the trial by Links 1988 eight subjects with HypoPP were enrolled in a double blind cross over study with acetazolamide (125 mg x 3 daily) or placebo being given for two weeks each. Muscle strength was measured in 11 muscle groups (hip adductors, hip flexors, knee extensors, knee flexors, shoulder abductors, elbow extensors, elbow flexors, wrist extensors, 3 point grip, neck extensors, and neck flexors) with a hand-held dynamometer every week and improved significantly in seven of eight participants. The mean strength during treatment weeks was significantly greater than during placebo weeks in all participants $(\mathrm{P}=0.05)$. Total muscle strength increased during the second acetazolamide week (mean increase: $10 \%$ ). Surface EMG measurement performed before and after treatment showed no change in the muscle fiber conduction velocity or power spectra. One participant withdrew from the study because of side effects of dizziness, nausea and tearfulness.

In one other placebo controlled double blind study (Ligtenberg 1996) of four participants with HypoPP, two showed improvement of muscle strength with pinacidil. Strength was measured using hand held myometer in four muscles (bilateral hip abductors and knee flexors) and was measured hourly during the three hour study period.

\section{HyperPP}

31 participants were enrolled: 15 assigned to the placebo/DCP sequence, and 16 to the $\mathrm{DCP} /$ placebo sequence.

Twenty-four of 31 participants completed both treatment phases. Seven participants withdrew from the trial: one was lost to followup in the run-in phase; two dropped out in the first nine-week wash out period, three participants dropped out in the first last eightweek treatment phase. Of these last three participants, two were in DCP, and the other one was taking placebo and was lost to followup. One subject dropped out in the last eight-week treatment phase, in DCP, for adverse effects.

Sixteen patients of 24 provided attack rate data for both treatment phases: the mean improvement in attack rate on DCP relative to placebo was significant $(P=0.006)$, and the mean improvement in severity-weighted attack rate on DCP relative to placebo was also significant $(\mathrm{P}=0.02)$.

When asked in a blinded fashion at the end of trial what treatment they preferred, 15 preferred DCP, one placebo and five their baseline medication (see Table 5).

The adverse effects in this group were similar to those observed in the HypoPP trial. One participant dropped out of the study because of adverse events (dizziness, difficulty concentrating at work) while taking DCP.

\section{DISCUSSION}

The finding of only two randomised controlled trials in the literature focusing on attack frequency and severity, implies that despite advances in molecular biology and cell physiology in the field of skeletal channelopathies, there is still a huge gap between our scientific knowledge and any evidence base for treatment strategies in PP. Studies on treatment strategies have been limited in the periodic paralyses probably due to the relatively 'benign' nature of the disorders because of the transitory nature of the paralytic episodes. However, increasing reports on the development of a limb-girdle myopathy show that some people with periodic paralysis may be as disabled as others with muscular dystrophies. The paucity of literature data on treatment in the periodic paralyses may also reflect the difficulties in constructing a trial in this group of disorders: the drop out rate may be exceedingly high to render a trial acceptable. Consider the Tawil trial in which there was nearly one fifth and one fourth, respectively in HyperPP and HypoPP, of drop out rate.

The study by Tawil and co-workers demonstrates the efficacy of DCP in reducing the frequency and severity of episodic weakness in PP. It shows that attack rates were significantly lower during the DCP phase than during the placebo phase in both the HypoPP and the HyperPP trials and that 17 of the 34 participants had to stop the placebo phase because the attack rate was intolerable. However, the clinical details of these participants were insufficient to identify a specific profile.

Previous studies with acetazolamide were single blind (Resnick 1968; Griggs 1970) or case reports (Raphael 1977) and were thus not considered in our data analysis. However, all suggested a beneficial effect of acetazolamide in reducing the frequency of attacks. The study by Tawil and workers did not address relative efficacy of acetazolamide versus dichlorphenamide although many patients were on acetazolamide before entering the study. A carryover effect was minimised in the study by Tawil and coworkers given the short half-life of acetazolamide. We have analysed other studies which have looked at the reduction of attack frequency and these have included several drugs in either hypokalemic periodic paralysis or hyperkalemic periodic paralysis (see tables for studies included and excluded in the review). ((i) nine participants with HypoPP were treated with Verapamil in a double blind trial (Links 1998). A positive effect with verapamil was not excluded; (ii) one participant with Hyper PP with metaprotenorol (Bendheim 1985), salbutamol (Hanna 1998; Wang 1976), DCP (Sander 1988); (iii) Verapamil and diaxozide are described in two clinical trials (Links 1998; Johnsen 1977b) to reduce the number of attacks in people with HypoPP. A trial on four participants with 
HypoPP (Johnsen 1977b) indicated no benefit in treatment with propranolol. Lithium did not seem to be beneficial in one participant with HyperPP (Pope 1984)). These studies were small nonradomised trials that did not in themselves offer certain alternative treatment options to acetazolamide or DCP.

When considering Andersen-Tawil syndrome still less information is available on treatment for the paralytic events (Djurhuus 1998; Junker 2002) so that no evidence based treatment can be recommended for this variety of periodic paralysis.

When considering muscle weakness and the potential limb-girdle myopathy that may be present in some of these people, still less information is available to define guidelines for preventive treatments. There are only a few studies with dichlorphenamide (Dalakas 1983; Links 1988), using a single-blind, placebo-controlled design, aimed at the prevention of persistent interattack weakness. These studies provide encouraging results on the use of dichlorphenamide or acetazolamide. The number of participants in these studies is however limited and despite clinical evidence the lack of genetic characterisation at the time represents a limitation to the interpretation of the results. This same limitation characterises another study with a potassium-channel opener, pinacidil. Ligtenberg and coworkers (Ligtenberg 1996), demonstrated an improvement in muscle strength in four people with hypokalemic periodic paralysis during attacks provoked with hyperglycaemic glucose clamp. Although encouraging these studies were too small and anecdotal. Although the carbonic acid anhydrase inhibitors are the current treatment options in HyperPP and HypoPP, further studies on a larger number of participants in multicentre studies are needed to define which drug is best for both periodic and interictal weakness comparing efficacy, side-effects and cost-benefits in the primary periodic paralyses.

\section{AUTHORS' CONCLUSIONS}

\section{Implications for practice}

In clinical practice a single double-blind randomised placebocontrolled cross-over trial and case reports on a limited number of participants suggest that carbonic acid anhydrase inhibitors reduce attack frequency and severity in the primary periodic paralyses. However there is insufficient information to say which of the carbonic acid anhydrase inhibitors (dichlorphenamide or acetazolamide) is more efficacious or has fewer side effects. If dichlorophenamide proves to be more efficacious than acetazolamide, as suggested by the study by Tawil, it is worth noting that the drug has been withdrawn by the manufacturers, except in Italy, for reasons other than safety and effectiveness. The best treatment for permanent muscle weakness in periodic paralysis has not been evaluated in any randomised trial. It is yet unclear whether attack frequency leads to permanent muscle weakness or whether reducing the attacks prevents this progression. The best treatment for attack frequency or permanent muscle weakness in the periodic paralysis associated with Andersen-Tawil syndrome has not been evaluated in any trial. In particular, in these forms of periodic paralysis treatment options are limited by the potential effects on the cardiac conduction system, which may be severely involved in Andersen-Tawil Syndrome.

\section{Implications for research}

Further research is needed to determine (i) if carbonic acid anhydrase inhibitors are indeed beneficial and if dichlorphenamide is better than acetazolamide when considering cost-benefit effects and side-effects; (ii) if permanent muscle weakness may be prevented or partially treated by these drugs; (iii) if specific mutations respond better than others with these drugs when considering both attack frequency and severity and permanent muscle weakness; (iv) if attacks of paralysis in Andersen-Tawil syndrome respond to the same drugs as the other primary periodic paralysis especially considering potential effects on the cardiac conduction system resulting from the electrolyte imbalance; (v) if treatment should start early in the disease course, no matter what the rate or severity of attacks, and if this approach could reduce the risk of developing a permanent myopathy.

\section{ACKNOWLEDGEMENTS}

We are particularly grateful to Kate Jewitt for continuous support in writing the review and providing additional technical information with the Cochrane review system. 
RE FERENCES

\section{References to studies included in this review}

Ligtenberg 1996 \{published data only\}

Ligtenberg JJ, Van Haeften TW, Van Der Kolk LE, Smit AJ, Sluiter WJ, Reitsma WD, et al.Normal insulin release during sustained hyperglycaemia in hypokalaemic periodicparalysis: role of the potassium channel opener pinacidil in impaired muscle strength. Clinical Science (London) 1996;91(5):583-9.

Links 1988 \{published data only\}

Links TP, Zwarts MJ, Oosterhuis HJ. Improvement of muscle strength in familial hypokalemic periodic paralysis with acetazolamide. Journal of Neurology, Neurosurgery and Psychiatry 1988;51(9):1142-5.

Tawil 2000 \{published and unpublished data\} Tawil R, McDermott MP, Brown R Jr, Shapiro BC, Ptacek LJ, McManis PG, et al.Randomized trials of dichlorphenamide in the periodic paralysis. Working Group on Periodic Paralyses. Annals of Neurology 2000;47(1): $46-53$.

\section{References to studies excluded from this review}

Bendheim 1985 \{published data only\}

Bendheim PE, Reale EO, Berg BO. Beta-Adrenergic treatment of hyperkalemic periodic paralysis. Neurology 1985;35 (5):746-9.

Brillman 1973 \{published data only\} Brillman J, Pincus JH. Myotonic periodic paralysis improved by negative sodium balance. Archives of Neurology 1973 July;29(1):67-9.

\section{Confavreux 1991 \{published data only\}} Confavreux C, Garassus P, Vighetto A, Aimard G. Familial hypokalemic periodic paralysis: prevention of paralytic attacks with lithium gluconate. Journal of Neurology, Neurosurgery and Psychiatry 1991;54(1):87-8.

Dalakas 1983 \{published data only\} Dalakas MC, Engel WK. Treatment of 'permanent' muscle weakness in familial hypokalemic periodic paralysis. Muscle \& Nerve 1983;6(3):182-6.

Djurhuus 1998 \{published data only\} Djurhuus MS, Klitgaard NA, Jensen BM, Andersen PE, Schroder HD. Multiple anomalies, hypokalaemic paralysis and partial symptomatic relief by terbutaline. Acta Paediatrica 1998 Apr;87(4):475-7.

Griggs 1983 \{published data only\} Griggs RC, Resnick J, Engel WK. Intravenous treatment of hypokalemic periodic paralysis. Archive of Neurology 1983; 40(9):539-40.

Hanna 1998 \{published data only\}

Hanna MG, Stewart J, Shapira AH, Wood NW, MorganHughes JA, Murray NM. Salbutamol treatment in a patient with hyperkalaemic periodic paralysis due to a mutation in the skeletal sodium channel gene (SCN4A). Journal of Neurology, Neurosurgery and Psychiatry 1998;65(2): 248-250.

Ikeda 2002 \{published data only\}

Ikeda K, Iwasaki Y, Kinoshita M, Yabuki D, Igarashi O, Ichikawa Y, et al.Acetazolamide-induced weakness in hypokalemic periodic paralysis. Internal Medicine 2002;41 (9):743-5.

Johnsen 1977a \{published data only\}

Johnsen. Treatment of familial periodic hypokalemia with propranolol (Inderal). Acta Neurologica Scandinavica 1977; 56(6):613-9.

Johnsen 1977b \{published data only\}

Johnsen T. Trial of the prophylactic effect of diazoxide in the treatment of familial periodic hypokalemia. Acta Neurologica Scandinavica 1977 Dec;56(6):525-32.

Junker 2002 \{published data only\} Junker J, Haverkamp W, Schulze-Bahr E, Eckardt L, Paulus W, Kiefer R. Amiodarone and acetazolamide for the treatment of genetically confirmed severe Andersen syndrome. Neurology 2002;59(3):466.

\section{Links 1994 \{published data only\}}

Links TP, Smit AJ, Molenaar WM, Zwarts MJ, Oosterhuis HJ. Familial hypokalemic periodic paralysis. Clinical, diagnostic and therapeutic aspects. Journal of the Neurological Sciences 1994;122(1):33-43.

Links 1998 \{published data only\}

Links TP, Arnoldus EP, Wintzen AR, van der Hoeven J, Gerritsen JJ, Brandenburg HC. The calcium channel blocker verapamil in hypokalemic periodic paralysis. Muscle \& Nerve 1998;21(11):1564-5.

Meola 2000 \{published data only\} Meola G, Sansone V. Therapy in myotonic disorders and in muscle channelopathies. Neurological Sciences 2000;21(5 suppl):S953-61.

Pope 1984 \{published data only\} Pope HG, Hudson JI, Poskanzer DC, Yurgelun-Todd D. Familial hyperkalemic periodic paralysis and bipolar disorder: a linkage and treatment study. Biological Psychiatry 1984 Oct;19(10):1449-59.

Raphael 1977 \{published data only\}

Raphael JC, Simon N, Goulon M. Paralysis with hypokalemia by transfer, treated by acetazolamide. Le Semaine des Hopitaux 1977 May 23;53(20):1167-70.

Riggs 1981 \{published data only\}

Riggs JE, Griggs RC, Moxley RT 3rd, Lewis ED. Acute effects of acetazolamide in hyperkalemic periodic paralysis. Neurology 1981;31(6):725-29.

Sander 1988 \{published data only\} Sander C. Therapy of paroxysmal hypokalemic paralysis: experience with diclofenamide. Monatsscchrift Kinderheilkunde 1988;136(3):149-50. 
Streib 1985 \{published data only\}

Streib EW. Beta-adrenergic treatment of hyperkalemic periodic paralysis. Neurology 1985;35(12):1805.

Thompson 1984 \{published data only\}

Thompson AJ, Hutchinson M. Myopathy in hypokalaemic periodic paralysis: reversal with acetazolamide. Irish Medical Journal 1984;77(6):171-2.

Torres 1981 \{published data only\}

Torres CF, Griggs RC, Moxley RT, Bender AN. Hypokalemic periodic paralysis exacerbated by acetazolamide. Neurology 1981;31(11):1423-8.

Vern 1987 \{published data only\}

Vern BA, Danon MJ, Hanlon K. Hypokalemic periodic paralysis with unusual responses to acetazolamide and sympathomimetics. Journal of the Neurological Sciences 1987;81(2-3):159-72.

Wang 1976 \{published data only\}

Wang P, Clausen T. Treatment of attacks in hyperkalaemic familial periodic paralysis by inhalation of salbutamol. Lancet 1976;1(7953):221-3.

\section{Additional references}

\section{Andersen 1971}

Andersen ED, Krasilnikoff PA, Overvad H. Intermittent muscular weakness, extrasystoles, and multiple developmental abnormalities: a new syndrome?. Acta Neurologica Scandinavica 1971;60(5):559-64.

\section{Bendahhou 2001}

Bendahhou S, Cummins TR, Griggs RC, Fu YH, Ptacek LJ. Sodium channel inactivation defects are associated with acetazolamide-exacerbated hypokalemic periodic paralysis. Annals of Neurology 2001;50(3):417-20.

Bendahhou 2003

Bendahhou S, Donaldson MR, Plaster NM, Tristani-Firouzi M, Fu YH, Ptacek LJ. Defective potassium channel Kir2.1 trafficking underlies Andersen-Tawil syndrome. Journal of Biological Chemistry 2003;278(51):51779-85.

\section{Donaldson 2004}

Donaldson MR, Yoon G, Fu YH, Ptacek LJ. AndersenTawil syndrome: a model of clinical variabiity, pleiotropy and genetic heterogeneity. Annals of Medicine 2004;36 (Suppl 1):92-7.

Fontaine 1990

Fontaine B, Khurana TS, Hoffman EP, Bruns GA, Haines JL, Trofatter JA, et al.Hyperkalemic periodic paralysis and the adult muscle sodium channel alpha-subunit gene. Science 1990;250(4983):1000-2.

Fontaine 1994

Fontaine B, Vale-Santos J, Jurkat-Rott K, Reboul J, Plassart E, Rime CS, et al.Mapping of the hypokalaemic periodic paralysis (HypoPP) locus to chromosome 1q31-32 in three European families. Nature Genetics 1994;6(3):267-72.

Griggs 1970

Griggs RC, Engel WK, Resnick JS. Acetazolamide treatment of hypokalemic periodic paralysis. Prevention of attacks and improvement of persistent weakness. Annals of Internal Medicine 1970;73(1):39-48.

\section{Heine 1993}

Heine R, Pika U, Lehmann-Horn F. A novel SCN4A mutation causing myotonia aggravated by cold and potassium. Human Molecular Genetics 1993;2:1349-53.

\section{Jurkat-Rott 1994}

Jurkat-Rott K, Lehmann-Horn F, Elbaz A, Heine R, Gregg RG, Hogan K, et al.A calcium channel mutation causing hypokalemic periodic paralysis. Human Molecular Genetics 1994;3(8):1415-9.

\section{Jurkat-Rott 2000}

Jurkat-Rott K, Mitrovic N, Hang C, Kousmekine A, Iaizzo P, Herzog J, et al.Voltage-sensor sodium channel mutations cause hypokalemic periodic paralysis type 2 by enhanced inactivation and reduced current. Proceedings of the National Academy of Sciences of the United States of America 2000;97 (17):9549-54.

\section{Links 1990}

Links TP, Zwarts MJ, Wilmink WM, Molenaar M, Oosterhuis HJ. Permanent muscle weakness in familial hypokalemic periodic paralysis. Brain 1990;113(Pt 6): 1873-89.

\section{McClatchey 1992}

McClatchey AI, McKenna-Yasek D, Cros D, Worthen HG, Kuncl RW, DeSilva SM, et al.Novel mutations in families with unusual and variable disorders of the skeletal muscle sodium channel. Nature Genetics 1992;2(2):148-52.

\section{McManis 1986}

McManis PG, Lambert EH, Daube JR. The exercise test in periodic paralysis. Muscle \& Nerve 1986;9(8):704-10.

\section{Plaster 2001}

Plaster NM, Tawil R, Tristani-Firouzi M, Canun S, Bendahhou S, Tsunoda A, et al.Mutations in Kir2.1 cause the developmental and episodic electrical phenotypes of Andersen's syndrome. Cell 2001;105(4):511-19.

Ptacek 1991

Ptacek LJ, George AL, Griggs RC, Tawil R, Kallen RG, Barchi RL, et al.Identification of a mutation in the gene causing hyperkalemic periodic paralysis. Cell 1991;67(5): 1021-27.

Ptacek 1992

Ptacek LJ, Tawil R, Griggs RC, Storvick D, Leppert M. Linkage of atypical myotonia congenita to a sodium channel locus. Neurology 1992;42(2):431-33.

\section{Ptacek 1994a}

Ptacek LJ, Tawil R, Griggs RC, Meola G, McManis P, Barohn $\mathrm{RJ}$, et al.Sodium channel mutations in acetazolamideresponsive myotonia congenita, paramyotonia congenita and hyperkalemic periodic paralysis. Neurology 1994;44(8): $1500-3$.

\section{Ptacek 1994b}

Ptacek LJ, Tawil R, Griggs RC, Engel AG, Layzer RB, Kwiecinski $\mathrm{H}$, et al.Dihydropyridine receptor mutations 
cause hypokalemic periodic paralysis. Cell 1994;77(6): 863-8.

\section{Resnick 1968}

Resnick JS, Engel WK, Griggs RC, Stam AC. Acetazolamide prophylaxis in hypokalemic periodic paralysis. New England Journal of Medicine 1968;278(11):582-6.

\section{Ricker 1983}

Ricker K, Bohlen R, Rohkamm R. Different effectiveness of tocainide and hydrochlorothiazide in paramyotonia congenita with hyperkalemic episodic paralysis. Neurology 1983;33(12):1615-18.

\section{Rojas 1991}

Rojas CV, Wang JZ, Schwartz LS, Hoffman EP, Powell BR, Brown RH Jr. A Met-to-Val mutation in the skeletal muscle $\mathrm{Na}+$ channel alfa-subunit in hyperkalaemic periodic paralysis. Nature 1991;354:387-9.

\section{Sansone 1997}

Sansone V, Griggs RC, Meola G, Ptacek LJ, Barohn R, Iannaccone $S$, et al.Andersen's syndrome: a distinct periodic paralysis. Annals of Neurology 1997;42(3):305-12.

\section{Sternberg 2001}

Sternberg D, Maisonobe T, Jurkat-Rott K, Nicole S, Launay

E, Chauveau D, et al.Hypokalemic periodic paralysis type 2 caused by mutations at codon 672 in the muscle sodium channel gene SCN4A. Brain 2001;124(Pt 6):1091-9.

\section{Tawil 1994}

Tawil R, Ptacek LJ, Pavlakis SG, DeVivo DC, Penn AS, Ozdemir C, et al.Andersen's syndrome: potassium-sensitive periodic paralysis, ventricular ectopy, and dysmorphic features. Annals of Neurology 1994;35(3):326-30.

\section{TristaniFirouzi 2002}

Tristani-Firouzi M, Jensen JL, Donaldson MR, Sansone

V, Meola G, Hahn A, et al.Functional and clinical characterization of KCNJ2 mutations associated with LQT7 (Andersen syndrome). The Journal of Clinical Investigation 2002;110(3):381-8.

* Indicates the major publication for the study 


\section{CHARACTERISTICS OF STUDIES}

\section{Characteristics of included studies [ordered by study ID]}

Ligtenberg 1996

\begin{tabular}{|c|c|c|}
\hline Methods & \multicolumn{2}{|c|}{ Randomised, double blind, placebo-controlled. } \\
\hline Participants & \multicolumn{2}{|c|}{4 participants with HypoPP, 8 matched controlled subjects. } \\
\hline Interventions & \multicolumn{2}{|l|}{ Pinacidl vs Placebo } \\
\hline Outcomes & \multicolumn{2}{|c|}{ Insulin sensitivity during hypergycemic glucose clamp. Improvement in muscle strength } \\
\hline \multicolumn{3}{|l|}{ Notes } \\
\hline \multicolumn{3}{|l|}{ Risk of bias } \\
\hline Item & Authors' judgement & Description \\
\hline Allocation concealment? & Yes & A - Adequate \\
\hline
\end{tabular}

Links 1988

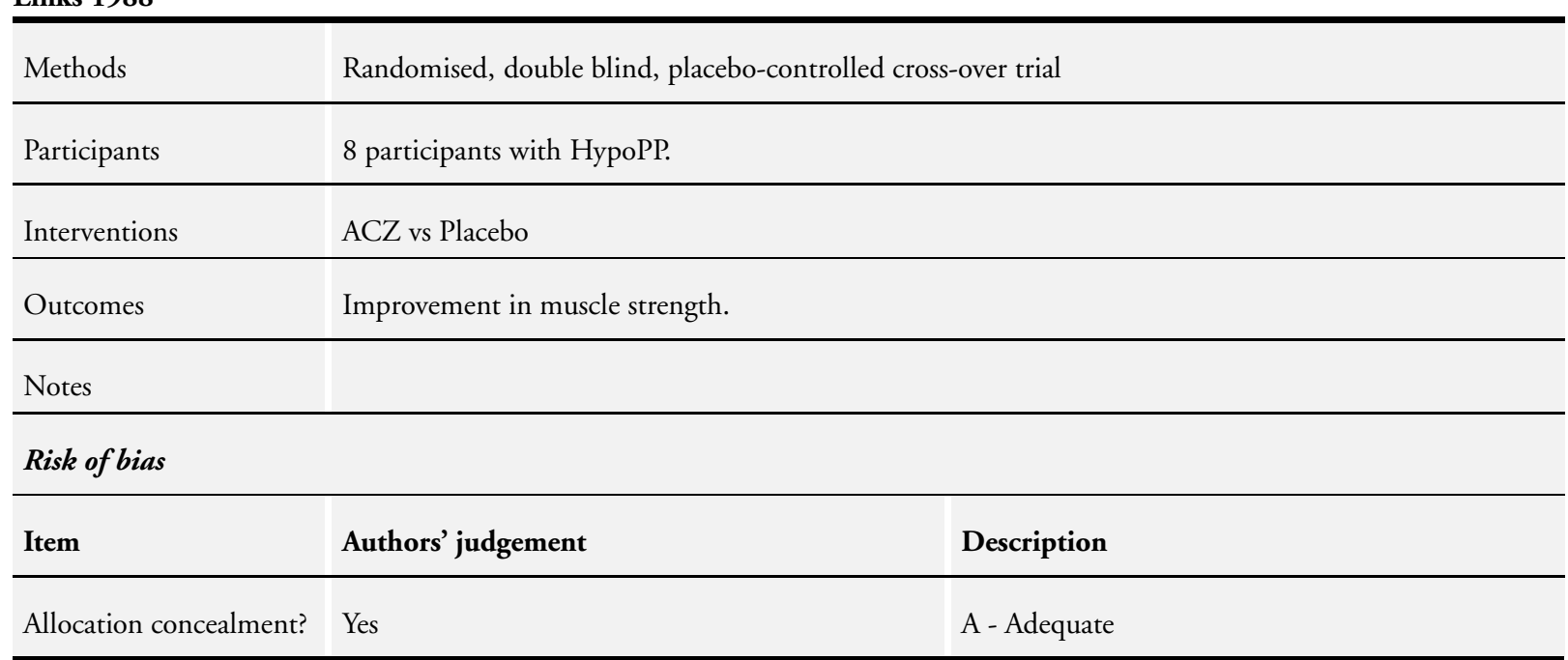

Tawil 2000

\begin{tabular}{ll}
\hline Methods & Multicentre, randomised, double-blind, placebo-controlled, cross-over trial \\
\hline Participants & $\begin{array}{l}42 \text { participants with Hypokalemic Periodic Paralysis. } \\
31 \text { Hyperkalemic Periodic Paralysis. }\end{array}$ \\
\hline Interventions & DCP vs placebo \\
\hline
\end{tabular}


Tawil 2000 (Continued)

\begin{tabular}{|c|c|c|}
\hline Outcomes & \multicolumn{2}{|c|}{$\begin{array}{l}\text { HypoPP: the primary outcome was the occurence of an intolerable increase in attack frequency or severity, } \\
\text { necessitating withdrawal from the treatment phase; a secondary outcome was the average number of attacks } \\
\text { per week over the final } 8 \text { weeks of each phase. HyperPP: the primary outcome variable was the average } \\
\text { number of attacks per week over the final } 8 \text { weeks of each phase; other secondary outcome variables were } \\
\text { severity-weighted attack rate and the preferred treatment }\end{array}$} \\
\hline \multicolumn{3}{|l|}{ Notes } \\
\hline \multicolumn{3}{|l|}{ Risk of bias } \\
\hline Item & Authors' judgement & Description \\
\hline Allocation concealment? & Yes & A - Adequate \\
\hline
\end{tabular}

Characteristics of excluded studies [ordered by study ID]

\begin{tabular}{|c|c|}
\hline Study & Reason for exclusion \\
\hline Bendheim 1985 & Case report only \\
\hline Brillman 1973 & Case report only \\
\hline Confavreux 1991 & Case report only \\
\hline Dalakas 1983 & Placebo-controlled case report. Not randomised and/or double blind \\
\hline Djurhuus 1998 & Case report only \\
\hline Griggs 1983 & Case report only \\
\hline Hanna 1998 & Case report only \\
\hline Ikeda 2002 & Case report only \\
\hline Johnsen $1977 \mathrm{a}$ & No randomisation \\
\hline Johnsen $1977 b$ & No randomisation \\
\hline Junker 2002 & Case report only \\
\hline Links 1994 & Case report only \\
\hline Links 1998 & Observational study only \\
\hline
\end{tabular}


(Continued)

\begin{tabular}{ll}
\hline Meola 2000 & Case report only \\
\hline Pope 1984 & Double blind but non-randomised trial \\
\hline Raphael 1977 & Case report only \\
\hline Riggs 1981 & Case report only \\
\hline Sander 1988 & Case report only \\
\hline Streib 1985 & Case report only \\
\hline Thompson 1984 & Case report only \\
\hline Torres 1981 & Single blind non-randomised trial \\
\hline Vern 1987 & Case report only \\
\hline Wang 1976 & No randomisation \\
\hline
\end{tabular}


DATA AND ANALYSES

Comparison 1. Comparison between HypoPP and HyperPP attack rate per week on DCP relative to placebo

\begin{tabular}{|c|c|c|c|c|}
\hline Outcome or subgroup title & $\begin{array}{l}\text { No. of } \\
\text { studies }\end{array}$ & $\begin{array}{c}\text { No. of } \\
\text { participants }\end{array}$ & Statistical method & Effect size \\
\hline $\begin{array}{l}1 \text { Mean improvement in attack } \\
\text { rate per week on DCP relative } \\
\text { to placebo }\end{array}$ & 1 & 33 & Mean Difference (IV, Fixed, 95\% CI) & $-1.4[-2.97,0.17]$ \\
\hline $\begin{array}{l}2 \text { Mean improvement in } \\
\text { severity-weighted attack rate } \\
\text { per week on DCP relative to } \\
\text { placebo }\end{array}$ & 1 & 33 & Mean Difference (IV, Fixed, 95\% CI) & $-3.50[-6.38,-0.62]$ \\
\hline
\end{tabular}

Analysis I.I. Comparison I Comparison between HypoPP and HyperPP attack rate per week on DCP relative to placebo, Outcome I Mean improvement in attack rate per week on DCP relative to placebo.

Review: Treatment for periodic paralysis

Comparison: I Comparison between HypoPP and HyperPP attack rate per week on DCP relative to placebo

Outcome: I Mean improvement in attack rate per week on DCP relative to placebo

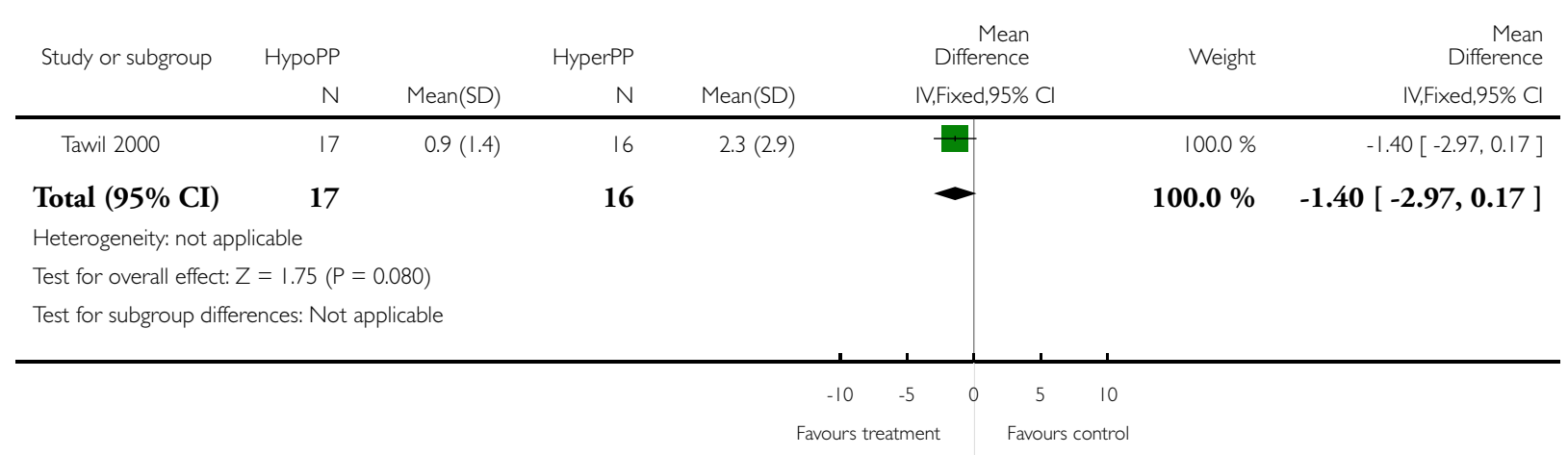


Analysis I.2. Comparison I Comparison between HypoPP and HyperPP attack rate per week on DCP relative to placebo, Outcome 2 Mean improvement in severity-weighted attack rate per week on DCP relative to placebo.

Review: Treatment for periodic paralysis

Comparison: I Comparison between HypoPP and HyperPP attack rate per week on DCP relative to placebo

Outcome: 2 Mean improvement in severity-weighted attack rate per week on DCP relative to placebo

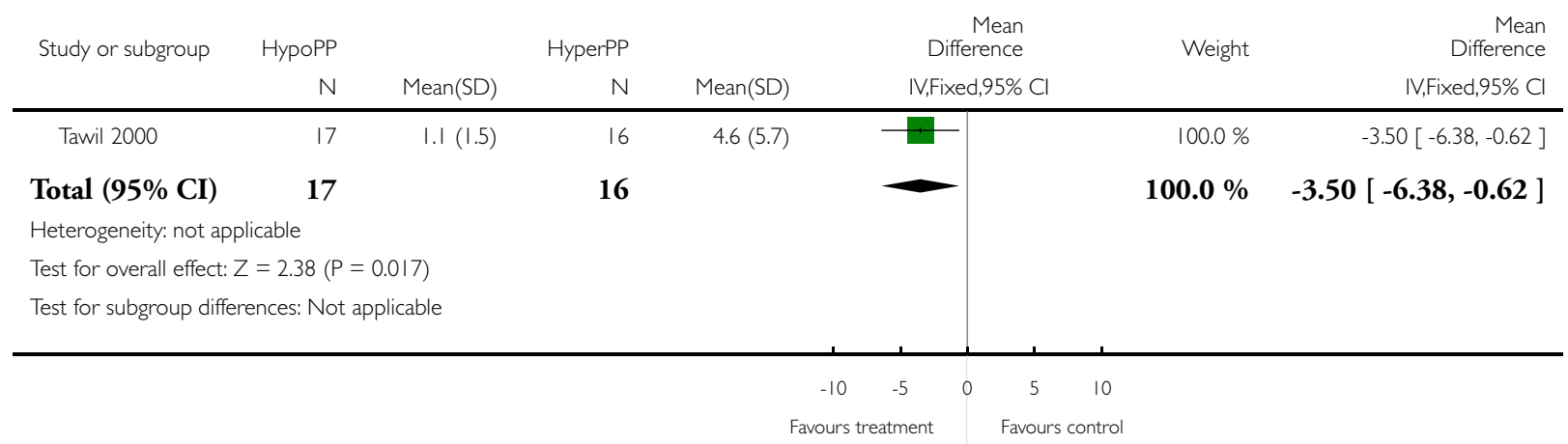

\section{ADDITIONAL TABLES}

Table 1. Diagnostic criteria for primary hypokalemic periodic paralysis

\section{Diagnostic criteria}

(1) Two or more attacks of muscle weakness with documented serum $\mathrm{K}<3.5 \mathrm{mEq} / \mathrm{L}$

(2) One attack of muscle weakness in the proband and one attack of weakness in one relative with documented serum $\mathrm{K}<3.5 \mathrm{mEq} /$ $\mathrm{L}$ in at least one attack

(3) Three of six clinical or laboratory features outlined below:

(a) Onset in the 1st or 2nd decade.

(b) Attack duration (muscle weakness involving one or more limbs) $>2$ hours.

(c) Positive triggers (high $\mathrm{CHO}$ rich meal, rest after exercise, stress).

(d) Improvement with potassium intake.

(e) Positive family history or genetically confirmed skeletal calcium or sodium channel mutation.

(f) Positive McManis short exercise test.

(4) Exclusion of other causes of hypokalaemia (renal, adrenal, thyroid dysfunction; renal tubular acidosis; diuretic and laxative abuse) 
Table 2. Diagnostic criteria for primary hyperkalemic periodic paralysis

\section{Diagnostic criteria}

(1) Two or more attacks of muscle weakness with documented serum $\mathrm{K}>4.5 \mathrm{mEq} / \mathrm{L}$

(2) One attack of muscle weakness in the proband and one attack of weakness in one relative with documented serum $\mathrm{K}>4.5 \mathrm{mEq} /$ $\mathrm{L}$ in at least one attack

(3) Three of six clinical or laboratory features outlined below:

(a) onset $<3$ rd decade

(b) attack duration (muscle weakness involving one or more limbs) $<2$ hours

(c) positive triggers (exercise, stress)

(d) myotonia

(e) positive family history or genetically confirmed skeletal sodium channel mutation

(f) positive McManis short exercise test

(4) Exclusion of other causes of hyperkalaemia (renal, adrenal, thyroid dysfunction; potassium-sparing diuretics use)

Table 3. Methodological quality of the included studies

\begin{tabular}{ll}
\hline Assessment criteria & Evaluation \\
\hline Secure method of randomisation & A \\
\hline Allocation concealment & A \\
\hline Blinding & A \\
\hline Completeness of follow up & B \\
\hline
\end{tabular}

Table 4. Outcomes in HypoPP patients (Tawil 2000)

\begin{tabular}{l|l}
$\begin{array}{l}\text { Primary outcome measure: reduction in severity or frequency at- } \\
\text { tacks }\end{array}$ & $\begin{array}{l}\text { Reduction of number of attacks per week from } 2.0757 \text { during } \\
\text { placebo phase to } 1.893 \text { during DCP phase }\end{array}$ \\
\hline Secondary outcome measures: change in muscle strength & Not considered in this study. \\
\hline Change in muscle mass (DEXA) & Not considered in this study. \\
\hline Change in Quality of Life & Not considered in this study. \\
\hline Preference of treatment strategy & $\begin{array}{l}15 / 42 \text { pts preferred DCP; } 3 / 42 \text { pts preferred placebo; 6/42 pre- } \\
\text { ferred their baseline medication (4 were taking nothing, } 1 \text { was } \\
\text { taking ACZ, } 1 \text { was taking DCP at baseline). Data were not deter- } \\
\text { mined for } 18 \text { patients }\end{array}$
\end{tabular}


Table 4. Outcomes in HypoPP patients (Tawil 2000) (Continued)

Adverse events

Table 5. Outcomes in HyperPP patients (Tawil 2000)

\begin{tabular}{l|l}
$\begin{array}{l}\text { Primary outcome measure: reduction in severity or frequency at- } \\
\text { tacks }\end{array}$ & $\begin{array}{l}\text { Reduction of number of attacks per week from } 3.798 \text { during } \\
\text { placebo phase to } 3.141 \text { during DCP phase }\end{array}$ \\
\hline Secondary outcome measures: change in muscle strength & Not considered in this study. \\
\hline Change in muscle mass (DEXA) & Not considered in this study. \\
\hline Change in Quality of Life & Not considered in this study. \\
\hline Preference of treatment strategy & $\begin{array}{l}15 / 31 \text { pts preferred DCP; } 1 / 31 \text { pts preferred placebo; } 5 / 31 \text { pre- } \\
\text { ferred their baseline medication (4 were taking nothing, } 1 \text { was } \\
\text { taking ACZ). Data were not determined for } 10 \text { patients }\end{array}$ \\
\hline Adverse effects & $\begin{array}{l}\text { Most common AE were paraesthesia (38\%) and cognitive symp- } \\
\text { toms (24\%), responsible for } 1 \text { drop out due to adverse events } \\
\text { (memory loss) }\end{array}$ \\
\hline
\end{tabular}

\section{A P P E N D I C E S}

\section{Appendix I. Ovid MEDLINE Search Strategy}

1. exp Paralyses, Familial Periodicl

2. (paralys $\$$ and periodic).mp.

3. (hypokalaemic or hypokalemic or hyperkalaemic or hyperkalemic).mp. [mp=title, original title, abstract, name of substance word, subject heading word]

4. 2 and 3

5. 1 or 4

6. randomized controlled trial.pt.

7. controlled clinical trial.pt.

8. randomized controlled trials/

9. random allocation/

10. double-blind method/

11. single-blind method/

12. or/6-11

13. animals/ not humans/

14. 12 not 13

Treatment for periodic paralysis (Review)

Copyright @ 2008 The Cochrane Collaboration. Published by John Wiley \& Sons, Ltd. 
15. clinical trial.pt.

16. exp clinical trials/

17. (clin\$ adj25 trial\$).ti,ab.

18. ((singl\$ or doubl\$ or tripl\$ or trebl\$) adj25 (blind\$ or mask\$)).ti,ab.

19. placebos/

20. placebo\$.ti,ab.

21. random\$.ti,ab.

22. research design/

23. or/ $15-22$

24. 23 not 13

25.24 not 14

26. comparative study/

27. exp evaluation studies/

28. follow up studies/

29. prospective studies/

30. (control\$ or prospectiv\$ or volunteer\$).ti,ab.

31. or $/ 26-30$

32. 31 not 13

33. 32 not (14 or 25$)$

34. 14 or 25 or 33

35.5 and 34

36. Andersen's Syndrome

37. Andersen- Tawil Syndrome and treatment or therapy

38. normokalemic periodic paralysis and treatment or therapy

39 Periodic paralysis and cardiac arrhythmias and treatment or therapy

\section{Appendix 2. Ovid EMBASE Search Strategy}

1. exp Periodic Paralysis/

2. (paralys\$ and periodic).mp.

3. (hypokalaemic or hypokalemic or hyperkalaemic or hyperkalemic).mp. [mp=title, abstract, subject headings, heading word, drug trade name, original title, device manufacturer, drug manufacturer name]

4. 2 and 3

5. 1 or 4

6. Randomized Controlled Trial/

7. Clinical Trial/

8. Multicenter Study/

9. Controlled Study/

10. Crossover Procedure/

11. Double Blind Procedure/

12. Single Blind Procedure/

13. exp RANDOMIZATION/

14. Major Clinical Study/

15. PLACEBO/

16. Meta Analysis/

17. phase 2 clinical trial/ or phase 3 clinical trial/ or phase 4 clinical trial/

18. (clin\$ adj25 trial\$).tw.

19. ((singl\$ or doubl\$ or tripl\$ or trebl\$) adj25 (blind $\$$ or mask $\$)$ ).tw.

20. placebo\$.tw.

21. random\$.tw.

22. control\$.tw.

23. (meta?analys\$ or systematic review\$).tw.

Copyright (@) 2008 The Cochrane Collaboration. Published by John Wiley \& Sons, Ltd. 
24. (cross?over or factorial or sham? or dummy).tw.

25. ABAB design $\$ . t w$.

26. or/6-25

27. human/

28. nonhuman/

29. 27 or 28

30. 26 not 29

31.26 and 27

32. 30 or 31

33.5 and 32

\section{WHAT'S NEW}

Last assessed as up-to-date: 13 November 2007.

\begin{tabular}{l|ll}
\hline Date & Event & Description \\
\hline 27 April 2008 & Amended & Converted to new review format. \\
\hline
\end{tabular}

\section{H I S T O R Y}

Protocol first published: Issue 3, 2004

Review first published: Issue 1, 2008

\begin{tabular}{lll}
\hline Date & Event & Description \\
\hline 14 November 2007 & New citation required and conclusions have changed & Substantive amendment \\
\hline
\end{tabular}

\section{CONTRIBUTIONS OFAUTHORS}

Valeria Sansone and Marta Panzeri wrote the review. Thera Links reviewed the papers together with Valeria Sansone and Marta Panzieri. Michael Rose helped with data analysis. Giovanni Meola and all other authors revised and discussed the paper. 


\section{DECLARATIONSOF INTEREST}

Doctors Sansone, Panzeri, Links and Meola are involved in the NIH-funded grant on acetazolamide versus dichlorphenamide in periodic paralyses.

\section{NDEX TERMS \\ Medical Subject Headings (MeSH)}

Acetazolamide [therapeutic use]; Carbonic Anhydrase Inhibitors [therapeutic use]; Dichlorphenamide [therapeutic use]; Hypokalemic Periodic Paralysis [* drug therapy]; Paralysis, Hyperkalemic Periodic [*drug therapy]; Pinacidil [therapeutic use]; Randomized Controlled Trials as Topic

\section{MeSH check words}

Humans 